\title{
Haemorrhage into a urachal cyst presenting as an 'acute abdomen'
}

\author{
Brian R. Davidson, Nicholas J. Brown and John P. Neoptolemos \\ Department of Surgery, Leicester Royal Infirmary, Leicester LE2 7LX, UK.
}

\begin{abstract}
Summary: A previously well 3 year old Asian girl presented as an emergency with the acute onset of generalized abdominal pain. On examination her abdomen was distended with generalized tenderness and guarding most marked centrally. Under anaesthesia a central abdominal mass arising from the pelvis was palpated which on proceeding to laparotomy was found to be a blood-filled urachal cyst. This was excised and her recovery was uneventful. Subsequent investigations have revealed no associated renal tract abnormalities.
\end{abstract}

\section{Introduction}

Urachal anomalies are rare developmental defects which may produce a cyst, sinus or fistula between the apex of the urinary bladder and the umbilicus. They usually present due to secondary infection. Spontaneous haemorrhage into a urachal cyst has not been previously reported.

\section{Case report}

A previously well 3 year old Asian girl presented with a one week history of intermittent abdominal discomfort and 9 hours of severe generalized pain associated with fever. She had not vomited or had any urinary or bowel upset. Her temperature was $37.5^{\circ} \mathrm{C}$ and she had a pulse rate of $140 / \mathrm{min}$. Examination of the abdomen was difficult because of severe abdominal pain but it appeared distended with generalized tenderness and guarding most marked centrally. Bowel sounds were present and rectal examination was normal.

The haemoglobin was $10.1 \mathrm{~g} / \mathrm{dl}$ and she had a neutrophil leucocytosis of $26.6 \times 10^{9} / \mathrm{dl}$; urine microscopy was normal.

A diagnosis of peritonitis, probably from a perforated acute appendicitis, was made and she was taken to the operating theatre. Under general anaesthesia a large central abdominal mass arising from the pelvis and extending up to the umbilicus was palpated. Catheterization of the bladder produced $50 \mathrm{ml}$ of urine

Correspondence: B.R. Davidson, F.R.C.S., 2 Sarson St, Quorn, Loughborough, Leicestershire, UK.

Accepted: 16 December 1986 but the mass persisted and a urachal cyst associated pathology was considered.

A right transverse lower abdominal incision was made. The appendix was normal and the mass was found to be a large blood-filled cyst lying in the midline extraperitoneally. The incision was extended transversely and the cyst dissected completely from the extraperitoneal tissues. The lower end of the cyst was found to form a fibrous cord adherent to the apex of the urinary bladder. Appendicectomy was also performed.

Post-operatively she required blood transfusion but otherwise made an uneventful recovery. Histological examination confirmed an epithelial lined cyst with collections of sinusoidal blood vessels with no evidence of malignancy. Subsequent ultrasonography of the renal tract revealed no abnormalities.

\section{Discussion}

The urachus represents a mesodermal remnant of the apex of the bladder which normally becomes a vestigial cord shortly after birth. Common abnormalities are sinuses, fistulae and cysts. ${ }^{1}$ Reported complications of urachal cysts are infection, ${ }^{2}$ urinary obstruction $^{3}$ and the development of malignant change; ${ }^{4}$ $0.34 \%$ of bladder carcinomas are malignancies of the urachus. ${ }^{5}$ Cysts should be managed by complete excision of the urachus in view of the possibility of recurrence and their malignant potential. As carcinoma of the urachus has not been reported in a child under 15 years of age, ${ }^{1}$ in children a transverse incision is satisfactory to allow complete excision of the 
urachus along with local excision of its entrance into the bladder. This is in keeping with the recommendations in standard paediatric texts. If infected, primary drainage with subsequent excision is recommended. ${ }^{6}$ Full investigation of the urinary tract is essential as associated anomalies may occur in up to $18 \%$ of children. $^{?}$

\section{References}

1. Blichert-Toft, M., Koch, F. \& Nielsen, O. Anatomic variants of the urachus related to clinical appearance and surgical treatment of urachal lesions. Surg Gynecol Obstet 1973, 137: 51-54.

2. Christensen, R., Crone,P. \& Hesselfeldt, P. Ruptured urachal cyst - a rare cause of peritonitis. Acta Chir Scand 1982, 148: 699-700.

3. Standfield, N. \& Shearer, R. Prostatism, obstructive uropathy and uraemia associated with a urachal cyst. $\mathrm{Br} J$ Urol 1981, 53: 482.

\section{Acknowledgement}

We wish to thank Mr D. Watkin for allowing us to report this case.

4. Loening, S.A., Jacobo, E., Hawtrey, C.E. \& Culp, D.A. Adenocarcinoma of the urachus. J Urol 1978, 119: 68-71.

5. Yu, H.H.Y. \& Leong, C.H. Carcinoma of the urachus: Report of one case and review of the literature. Surgery 1975, 77: 726-729.

6. MacMillan, R.W., Schullinger, J.N. \& Santulli, T.V. Pyourachus: an unusual surgical problem. J Pediatr Surg 1973, 8: 387-389.

7. Herbst, W.P. Patent urachus. South Med J 1937, 30: 711 719. 